\title{
不溶性ガスと吸湿性溶液の接触装置の動特性 ${ }^{\dagger}$
}

\author{
川島 美 勝 - 増 淵 正 美* \\ 横浜国立大学工学部 横浜市南区大岡 2-31-1
}

(昭和 43 年 12 月 25 日受付)

\section{Dynamic Analysis of a Dehumidification Process with Gas and Liquid Phase}

\author{
Yoshikatsu Kawashima and Masami Masubuchi \\ (Faculty of Engıneering, Yokohama National University, Yokohama) \\ (Recelved December 25, 1968)
}

\begin{abstract}
This paper presents the dynamic behavior of the dehumidification process which has heat and mass transfer resistances on both gas and liquid sides.

Simplified two lumped systems which assume a gas bulk and a liquid bulk are considered. The double film theory to the distributions of concentration and temperature near the interface is used. Basic differential equations are obtained from the heat- and mass-balance relations. The equations are linearized and non-dimensionalized near the steady state and the block diagram and the transfer matrix are obtaind. A numerical example is also shown.

The result shows that there exists an interaction of heat and mass transfer, which depends on the temperature sensitivity of the gas-liquid equilibrium relationship, latent heat of evaporation of water and heat of dilution. The second result is that the over-all mass transfer coefficient is not constant and is shown as a function of transfer frequency when the input temperature of gas and liquid are constant and the humidity of the inlet gas and the concentration of the inlet liquid are variable.
\end{abstract}

\section{1. は しがき}

湿分を含んだ不溶性ガスと吸湿性溶液を接触させる と，熱移動の他に湿分の移動すなわち物質移動が起こ る.

この性質を利用した気液接触装置は広い応用範用を 持ち, 特に空気調和に执いては, 冷却法, 圧縮法に比 較して必要以上の熱的・機械的エネルギを浪費せず，ま た固体吸湿剤と異なり取扱いやすく,かつ, 連続操作も 可能なので，大量の空気を処理する方法としての優位 さが認められ，近年すでに実用の段階にはいっている。

この接触装置を各種プラントに応用するさい, 特に 制御系の設計においては，静特性はもちろんであるが， 動特性の知識が不可欠である.

$\dagger$ 第 9 回自動制御連合講演会 (昭 $41 \cdot 10 \cdot 11$ ), 機珹学会 第 45 期通常総会学術講演会 (昭 $43 \cdot 4 \cdot 3$ ) て発表.

* (現) 大阪大学工学部
気液界面に招ける非定常移動現象については，高 松1)らの研究があるが，接触装置の動特性に関するも のは見めたらない。

本交では, 気液両相に熱拉よび物質移動の抵抗が存 在する場合の動特性を周波数特性によって理論的に求 めた、委た熱移動と物質移動の相互干渉の存在を示し, これがぞのような形でなされるかを検討し，相互干渉 を無視した場合との比較を行ない, 総括物質移動係数 の新しい理論式を提案し, 従来のように一定值とはな らず熱移動の影響を受けて, 伝達周波数の関数となる ことを示した。

\section{2. 記 号}

$a:$ 界面面積 $\left[\mathrm{m}^{2}\right]$

$C_{l i}:$ 流入液濃度 $\left[\mathrm{kg}-\mathrm{H}_{2} \mathrm{O} / \mathrm{kg}\right.$-solvent $]$

$C_{l}:$ 流出液濃度 $\left[\mathrm{kg}-\mathrm{H}_{2} \mathrm{O} / \mathrm{kg}\right.$-solvent $]$

$C_{i}:$ 界面濃度 $\left[\mathrm{kg}-\mathrm{H}_{2} \mathrm{O} / \mathrm{kg}\right.$-solvent $]$ 
$C_{p g}:$ 気体比熱 $[\mathrm{kcal} / \mathrm{kg}-\mathrm{dry} \mathrm{gas} \cdot \mathrm{deg}]$

$C_{p l}:$ 液体比熱 $[\mathrm{kcal} / \mathrm{kg}$-solvent.deg]

$F_{g}:$ 気体流量 $[\mathrm{kg}$-dry gas $/ \mathrm{h}]$

$F_{l}:$ 液体流量 $[\mathrm{kg}$-solvent $/ \mathrm{h}]$

$H_{g i}$ : 流入気体湿度 $\left[\mathrm{kg}-\mathrm{H}_{2} \mathrm{O} / \mathrm{kg}\right.$-dry gas $]$

$H_{g}:$ 流出気体湿度 $\left[\mathrm{kg}-\mathrm{H}_{2} \mathrm{O} / \mathrm{kg}\right.$-dry gas $]$

$H_{\imath}$ : 界面湿度 [kg- $\mathrm{H}_{2} \mathrm{O} / \mathrm{kg}$-dry gas $]$

$h_{g}$ : 気体側境膜熱移動係数 $\left[\mathrm{kcal} / \mathrm{h} \cdot \mathrm{m}^{2} \cdot \mathrm{deg}\right]$

$h_{l}$ : 液体側境膜熱移動係数 $\left[\mathrm{kcal} / \mathrm{h} \cdot \mathrm{m}^{2} \cdot \mathrm{deg}\right]$

$K_{g}$ : 気体側境膜物質移動係数 $\left[\mathrm{kg}-\mathrm{H}_{2} \mathrm{O} / \mathrm{h} \cdot \mathrm{m}^{2} \cdot \Delta H\right]$

$K_{l}$ : 液体側境膜物質移動係数 $\left[\mathrm{kg}-\mathrm{H}_{2} \mathrm{O} / \mathrm{h} \cdot \mathrm{m}^{2} \cdot \Delta \mathrm{C}\right]$

$N_{i}$ : 界面を通過与る物質移動量 $\left[\mathrm{kg}-\mathrm{H}_{2} \mathrm{O} / \mathrm{h} \cdot \mathrm{m}^{2}\right]$

$Q_{i}$ : 界面を通過する熱移動量 $\left[\mathrm{kcal} / \mathrm{h} \cdot \mathrm{m}^{2}\right]$

$Q_{g}:$ 気体側から気体側境界層にはいる熱栘動量

$\left[\mathrm{kcal} / \mathrm{h} \cdot \mathrm{m}^{2}\right]$

$V_{g}:$ 気体容積 $\left[\mathrm{m}^{3}\right]$

$V_{l}:$ 液体容積 $\left[\mathrm{m}^{3}\right]$

$\gamma_{g}:$ 気体比重量 $\left[\mathrm{kg}\right.$-dry gas $\left./ \mathrm{m}^{3}\right]$

$\gamma_{l}:$ 液体比重量 $\left[\mathrm{kg}\right.$-solvent $\left./ \mathrm{m}^{3}\right]$

$\theta_{g i}:$ 流入気体温度 $\left[{ }^{\circ} \mathrm{C}\right]$

$\theta_{g}:$ 流出気体温度 $\left[{ }^{\circ} \mathrm{C}\right]$

$\theta_{l i}:$ 流入液体温度 $\left[{ }^{\circ} \mathrm{C}\right]$

$\theta_{l}:$ 流出液体温度 $\left[{ }^{\circ} \mathrm{C}\right]$

$\theta_{i}:$ 界面温度 $\left[{ }^{\circ} \mathrm{C}\right]$

$\lambda:$ 凝縮熱 $\left[\mathrm{kcal} / \mathrm{kg}-\mathrm{H}_{2} \mathrm{O}\right]$

$-\Delta H:$ 融界拈よび希釈熱 $\left[\mathrm{kcal} / \mathrm{kg}-\mathrm{H}_{2} \mathrm{O}\right]$

$t:$ 時間 [h]

$s:$ 定常状態を示す添字

$\Delta:$ 定常状態值からの偏差を示す

$S:$ 無次元時間 $t^{\prime}$ に関するラプラス演算子

\section{3. 基礎方程 式 ${ }^{3) ~ 5)}$}

気液接触装置を Fig. 1 のよう気相之液相の二集 中系として扱い, 気液界面付近の温度招よび濃度分布 を Fig. 2 のように考克，さらに次の仮定を設ける.

1. 各流体の物性値, 物質移動係数は一定.

2. 各流体の入口流量は一定.

3. 各流体の流動状態は変わらないものとし, 気液

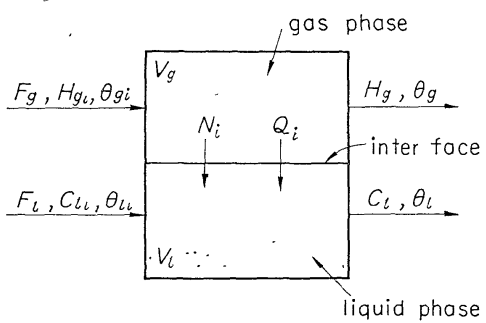

Fig. 1 Schematic diagram of the dehumidification process
容積比, 界面面積は一定.

4. 物質移動量は入口流量に比較して非常に少ない。

5. 囲壁，充てん物などとの熱交換は無視する。

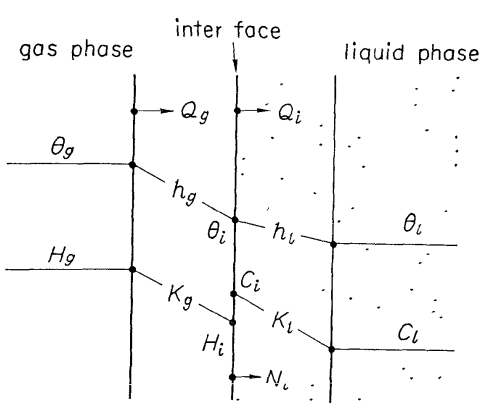

Fig. 2 Concentration and temperature profiles near the inter face

界面の気液は平衡に達していると考光られるから， 界面温度 $\theta_{i}$, 界面濃度 $C_{i}$, 界面湿展 $H_{2}$ の間の関係 を次の上うに表わす。

$$
H_{i}=f\left(\theta_{i}, C_{i}\right)
$$

気体側境膜を気相から界面一通過する物質移動量 $N_{i}$ は気相の湿度 $H_{g}$ と界面の湿度 $H_{2}$ との差に比例 乙，比例定数すなわち気体側境膜物質移動係数を $K_{g}$ とすれば, 次式が成立つ。

$$
N_{i}=K_{g}\left(H_{g}-H_{i}\right)
$$

液側境膜を界面から液相へ通過する物質移動量は, 気体側境膜を通過する量 $N_{i}$ に等しく, 界面の濃度 $C_{i}$ 之液相の濃度 $C_{l}$ との差に比例し, 液体側境膜物質移 動係数を $K_{l}$ とすれば，次式が成立つ。

$$
N_{i}=K_{l}\left(C_{i}-C_{l}\right)
$$

気体側境膜を気相から界面へ通過する熱移動量 $Q_{g}$ は気相の温度 $\theta_{g}$ と界面の温度 $\theta_{i}$ との差に比例し, 気体側境膜熱移動係数を $h_{g}$ とすれば, 次式が成立つ.

$$
Q_{g}=h_{g}\left(\theta_{g}-\theta_{\hat{\imath}}\right)
$$

液側境膜を界面から液相へ通過する熱移動量 $Q_{\imath}$ は, 界面の温度 $\theta_{2}$ と液相の温度 $\theta_{l}$ との差に比例し, 液 体側境膜熱移動係数を $h_{l}$ とすれば，次式が成立つ.

$$
Q_{i}=h_{l}\left(\theta_{i}-\theta_{l}\right)
$$

水の凝縮熱を $\lambda$ とすると各移動量の間には次の関係 がある。

$$
Q_{i}=Q_{g}+\lambda N_{i}
$$

気相について, 物質収支を考光ると, 次式が成立つ.

$$
V_{g} r_{g} \frac{d H_{g}}{d t}=F_{g} H_{g i}-F_{g} H_{g}-N_{\imath} a
$$

ここで，右辺の第 1 項は流入する気体の持込先湿分 の量であり，第 2 項は流出する気体の持出す量であり, 第 3 項は界面を通して液相へ移動する量である，左辺 は気相に貯えられる湿分の量を示す。 
液相について，物質收支を考光ると，

$$
V_{l} r_{l} \frac{d C_{l}}{d t}=F_{l}\left(C_{l i}-C_{l}\right)+N_{i} a
$$

同様にして，気相，液相について扔の扮の熱収支を 考光ると，

$$
\begin{gathered}
C_{p g} V_{g} \gamma_{g} \frac{d \theta_{g}}{d t}=F_{g} C_{p g}\left(\theta_{g i}-\theta_{g}\right)-Q_{g} a \\
C_{p l} V_{l} \gamma_{l} \frac{d \theta_{l}}{d t}=F_{l} C_{p l}\left(\theta_{l i}-\theta_{l}\right)+Q_{i} a+(-\Delta H) N_{\imath} a
\end{gathered}
$$

(10) 式の右辺の第 3 項は, 気相から液相に移動した 水分の溶解拉よび希釈による発熱量である.

以上の（1）（10）式が，接触装置の基礎方程式で あり, 定常状態はこれらの微分の項を零々置いた代数 式をとくことによって求められる。

\section{4. 基礎方程式の線形化之無次元化}

（1）式の気液平衡関係は非線形ではあるが, 定常状 態付近では, 直線関係汇西ると考えてよいので, 定常 状態のまわりで局所線形化して扱らことにする.

$$
H_{i}=m \Delta \theta_{i}+n \Delta C_{i}+H_{i s}
$$

ただし， $m=\left(\frac{\partial H_{i}}{\partial \theta_{i}}\right)_{s}, n=\left(\frac{\partial H_{i}}{\partial C_{i}}\right)_{s}$

定常状態からの恋化分のみを考党ることとし次のよ らに拉く。

$$
\begin{array}{lll}
\Delta H_{i}=H_{i}-H_{i s} & \Delta C_{i}=C_{i}-C_{i s} & \Delta \theta_{i}=\theta_{i}-\theta_{i s} \\
\Delta N_{i}=N_{i}-N_{l s} & \Delta Q_{i}=Q_{i}-Q_{i s} & \Delta Q_{g}=Q_{g}-Q_{g s} \\
\Delta H_{g i}=H_{g i}-H_{g i s} & \Delta C_{l i}=C_{l i}-C_{l i s} & \Delta \theta_{g i}=\theta_{g i}-\theta_{g i s} \\
\Delta \theta_{l i}=\theta_{l i}-\theta_{l 2 s} & \Delta H_{g}=H_{g}-H_{g s} & \Delta C_{l}=C_{l}-C_{l s} \\
\Delta \theta_{g}=\theta g-\theta_{g s} & \Delta \theta_{l}=\theta_{l}-\theta_{l s} &
\end{array}
$$

これらを用いて，(2)〜(11) 式を書き直すと。

$$
\begin{aligned}
\Delta H_{i} & =m \Delta \theta_{i}+n \Delta C_{i} \\
\Delta N_{i} & =K_{g}\left(\Delta H_{g}-\Delta H_{i}\right) \\
\Delta N_{i} & =K_{l}\left(\Delta C_{i}-\Delta C_{l}\right) \\
\Delta Q_{g} & =h_{g}\left(\Delta \theta_{g}-\Delta \theta_{i}\right) \\
\Delta Q_{i} & =h_{l}\left(\Delta \theta_{i}-\Delta \theta_{l}\right) \\
\Delta Q_{i} & =\Delta Q_{g}+\lambda \Delta N_{i}
\end{aligned}
$$$$
V_{g} \gamma_{g} \frac{d \cdot \Delta H_{g}}{d t}=F_{g}\left(\Delta H_{g i}-\Delta H_{g}\right)-a \cdot \Delta N_{i}
$$$$
V_{l} \gamma_{l} \frac{d \cdot \Delta C_{l}}{d t}=F_{l}\left(\Delta C_{l i}-\Delta C_{l}\right)+a \cdot \Delta N_{i}
$$

$$
C_{p g} V_{g} \gamma_{g} \frac{d \cdot \Delta \theta_{g}}{d t}=F_{g} C_{p g}\left(\Delta \theta_{g i}-\Delta \theta_{g}\right)-a \cdot \Delta Q_{g}
$$

$$
\begin{aligned}
C_{p l} V_{l} r_{l} \frac{d \cdot \Delta \theta_{l}}{d t}= & F_{l} C_{p l}\left(\Delta \hat{\theta}_{l i}-\Delta \theta_{l}\right)+a \cdot \Delta Q_{i} \\
& +(-\Delta H) a \cdot \Delta N_{i}
\end{aligned}
$$

基礎方程式に一般性を持たせるために，変数拉よび パラメータを無次元化することとし，無次元化のため
の基準の量として,

$$
\begin{array}{lll}
N=N_{i s} & Q=Q_{g s} & H=H_{g i s}-H_{g s} \\
C=C_{l s}-C_{l i s} & \theta=\theta_{g i s}-\theta_{g s} & T=\left(V_{g} \gamma_{g}\right) / F_{g}
\end{array}
$$

を設け，この基準量で対応する各変数を割ったものを 無次元変数とし次のよう飞'を付けて表わす。

$$
\begin{array}{lll}
H_{i}{ }^{\prime}=\Delta H_{i} / H & C_{i}{ }^{\prime}=\Delta C_{i} / C & \theta_{i}{ }^{\prime}=\Delta \theta_{i} / \theta \\
N_{i}{ }^{\prime}=\Delta N_{i} / N & Q_{i}{ }^{\prime}=\Delta Q_{i} / Q & Q_{g}{ }^{\prime}=\Delta Q_{g} / Q \\
H_{g i}{ }^{\prime}=\Delta H_{g i} / H & C_{l i}{ }^{\prime}=\Delta C_{l i} / C & \theta_{g i}{ }^{\prime}=\Delta \theta_{g i} / \theta^{\prime} \\
\theta_{l i}{ }^{\prime}=\Delta \theta_{l i} / \theta & H_{g}{ }^{\prime}=\Delta H_{g} / H & C^{\prime}=\Delta C_{l} / C \\
\theta_{g}{ }^{\prime}=\Delta \theta_{g} / \theta & \theta_{l}{ }^{\prime}=\Delta \theta_{l} / \theta & t^{\prime}=t / T
\end{array}
$$

パラメータも次のように無次元化する.

$$
\begin{array}{lcc}
m^{\prime}=m(\theta / H) & n^{\prime}=n(C / H) & K_{g}{ }^{\prime}=K_{g}(H / N), \\
K_{l}{ }^{\prime}=K_{l}(C / N) & h_{g}{ }^{\prime}=h_{g}(\theta / Q) & h_{l}{ }^{\prime}=h_{l}(\theta / Q) \\
\lambda^{\prime}=\lambda(N / Q) & (-\Delta H)^{\prime}=(-\Delta H)(N / Q) \\
k=\left(V_{l} \gamma_{l}\right) /\left(F_{l} T\right) & k_{2}=(a Q) /\left(F_{l} C_{p l} \theta\right)
\end{array}
$$

これらを用いて，(12)〜 (21) 式を書き換觉ると，

$$
\left\{\begin{array}{l}
H_{i}{ }^{\prime}=m^{\prime} \theta_{i}{ }^{\prime}+n^{\prime} C_{i}{ }^{\prime} \\
N_{i}{ }^{\prime}=K_{g}{ }^{\prime}\left(H_{g}{ }^{\prime}-H_{i}{ }^{\prime}\right) \\
N_{i}{ }^{\prime}=K_{l}{ }^{\prime}\left(C_{\imath}{ }^{\prime}-C_{l}{ }^{\prime}\right) \\
Q_{g}{ }^{\prime}=h_{g}{ }^{\prime}\left(\theta_{g}{ }^{\prime}-\theta_{i}{ }^{\prime}\right) \\
Q_{i}{ }^{\prime}=h_{l}{ }^{\prime}\left(\theta_{i}{ }^{\prime}-\theta_{l}{ }^{\prime}\right) \\
Q_{i}{ }^{\prime}=Q_{g}{ }^{\prime}+\lambda^{\prime} N_{i}{ }^{\prime} \\
\frac{d H_{g}{ }^{\prime}}{d t^{\prime}}=\left(H_{g i}{ }^{\prime}-H_{g}{ }^{\prime}\right)-N_{i}{ }^{\prime} \\
k \frac{d C_{l}{ }^{\prime}}{d t^{\prime}}=\left(C_{l i}{ }^{\prime}-C_{l}{ }^{\prime}\right)+N_{i}{ }^{\prime} \\
\frac{d \theta_{g}{ }^{\prime}}{d t^{\prime}}=\left(\theta_{g i}{ }^{\prime}-\theta_{g}{ }^{\prime}\right)-Q_{g}{ }^{\prime} \\
k \frac{d \theta_{l}{ }^{\prime}}{d t^{\prime}}=\left(\theta_{l i}{ }^{\prime}-\theta_{l}{ }^{\prime}\right)+k_{2}\left(\theta_{i}{ }^{\prime}+(-\Delta H)^{\prime} N_{i}{ }^{\prime}\right)
\end{array}\right.
$$

以下，この無次元化した基礎式に基づいて議論を進 めるが，無次元変数を意味する'は表現が繁雑になる ので省略する。

\section{5. 伝 達 関 数}

(22)，(23)，(24）式より $H_{i}, N_{i}$ を消去すると，

$$
K_{g}\left(H_{g}-m \theta_{i}-n C_{i}\right)=K_{l}\left(C_{\imath}-C_{l}\right)
$$

(25)，(26)，(27）式より $N_{i}, Q_{g}, Q_{i}$ を消去すると, $h_{g}\left(\theta_{g}-\theta_{i}\right)+\lambda K_{l}\left(C_{i}-C_{l}\right)=h_{l}\left(\theta_{i}-\theta_{l}\right)$

(32), (33) 式を $\theta_{\imath}, C_{2}$ についてとくと,

$$
\begin{aligned}
& \theta_{i}= \frac{\lambda K_{l}\left(K_{g} H_{g}+K_{l} C_{l}\right)}{\lambda m K_{g} K_{l}} \\
& \frac{+\left(K_{g} n+K_{l}\right)\left(h_{g} \theta_{g}-\lambda K_{l} C_{l}+h_{l} \theta_{l}\right)}{+\left(h_{g}+h_{l}\right)\left(K_{g} n+K_{l}\right)} \\
& C_{i}=\frac{-K_{g} m\left(h_{g} \theta_{g}-\lambda K_{l} C_{l}+h_{l} \theta_{l}\right)}{\lambda m K_{g} K_{l}} \\
& \frac{+\left(h_{g}+h_{l}\right)\left(K_{g} H_{g}+K_{l} C_{l}\right)}{+\left(h_{g}+h_{l}\right)\left(K_{g} n+K_{l}\right)}
\end{aligned}
$$


（34）式を（25）式に代入すると.

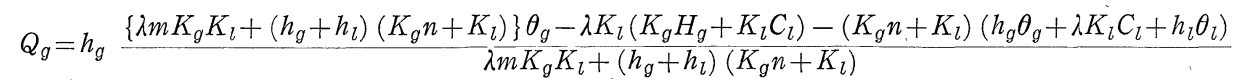

(35) 式を(24) 式炕代入すると,

$$
N_{i}=K_{l} \frac{-K_{g} m\left(h_{g} \theta_{g}-\lambda K_{l} C_{l}+h_{l} \theta_{l}\right)+\left(h_{g}+h_{l}\right)\left(K_{g} H_{g}+K_{l} C_{l}\right)-\left\{\lambda m K_{g} K_{l}+\left(h_{g}+h_{l}\right)\left(K_{g} n+K_{l}\right)\right\} C_{l}}{\lambda m K_{g} K_{l}+\left(h_{g}+h_{l}\right)\left(K_{g} n+K_{l}\right)}
$$

この (36)，(37）を(28)〜(31) 飞代入すると,

$$
\left\{\begin{array}{l}
\frac{d H_{g}}{d t}=\left(H_{g i}-H_{g}\right)-\left(b_{1} H_{g}-b_{2} \theta_{g}-b_{3} \theta_{l}-b_{4} C_{l}\right) \\
k \frac{d C_{l}}{d t}=\left(C_{l i}-C_{l}\right)+\left(b_{1} H_{g}-b_{2} \theta_{g}-b_{3} \theta_{l}-b_{4} C_{l}\right) \\
\frac{d \theta_{g}}{d t}=\left(\theta_{g i}-\theta_{g}\right)-\left(-b_{5} H_{g}+b_{6} \theta_{g}-b_{7} \theta_{l}+b_{8} C_{l}\right) \\
k \frac{d \theta_{l}}{d t}=\left(\theta_{l i}-\theta_{l}\right)+k_{2}\left(-b_{5} H_{g}+b_{6} \theta_{g}-b_{7} \theta_{l}+b_{8} C_{l}\right)
\end{array}\right.
$$

$$
\begin{gathered}
\nearrow \text { ただし }, k_{3}=k_{2}(\lambda+(-\Delta H)) \quad b_{1}=\frac{1}{z}\left(\frac{1}{h_{g}}+\frac{1}{h_{l}}\right) \\
b_{2}=\frac{1}{z} \cdot \frac{n}{h_{l}} \quad b_{3}=\frac{1}{z} \cdot \frac{m}{h_{g}} \quad b_{4}=\frac{1}{z}\left(\frac{1}{h_{g}}+\frac{1}{h_{l}}\right) n \\
b_{5}=\frac{1}{z} \cdot \frac{\lambda}{h_{l}} \quad b_{6}=\frac{1}{z}\left(\frac{\lambda m}{h_{l}}+\frac{n}{K_{l}}+\frac{1}{K_{g}}\right) \quad b_{7}=\frac{1}{z}\left(\frac{n}{K_{l}}+\frac{1}{K_{g}}\right) \\
b_{8}=\frac{1}{z} \frac{\lambda n}{h_{l}} \quad z=\frac{\lambda m}{h_{g} h_{l}}+\left(\frac{1}{h_{g}}+\frac{1}{h_{l}}\right)\left(\frac{1}{K_{g}}+\frac{n}{K_{l}}\right)
\end{gathered}
$$

(38)〜 (41) 式をラプラス変換し,初期值をゼロと特 きマトリクスで表示すれば,

$$
\left[\begin{array}{l}
H_{g i}(s) \\
\theta_{g i}(s) \\
\theta_{l i}(s) \\
C_{l i}(s)
\end{array}\right]=\left[\begin{array}{cccc}
s+1+b_{1} & -b_{2} & -b_{3} & -b_{4} \\
-b_{5} & s+1+b_{6} & -b_{7} & b_{8} \\
k_{2} b_{5}-k_{3} b_{1} & -k_{2} b_{6}+k_{3} b_{2} & k s+1+k_{2} b_{7}+k_{3} b_{3} & -k_{2} b_{8}+k_{3} b_{4} \\
-b_{1} & b_{2} & b_{3} & k s+1+b_{4}
\end{array}\right]\left[\begin{array}{c}
H_{g}(s)^{-} \\
\theta_{g}(s) \\
\theta_{l}(s) \\
C_{l}(s)
\end{array}\right]
$$

したがって, 右辺の係数マトリクスの逆マトリクスを求め, $\boldsymbol{G}(s)$ とすれば,

$$
\left[\begin{array}{c}
H_{g}(s) \\
\theta_{g}(s) \\
\theta_{l}(s) \\
C_{l}(s)
\end{array}\right]=\left[\begin{array}{llll}
g_{11}(s) & g_{12}(s) & g_{13}(s) & g_{14}(s) \\
g_{21}(s) & g_{22}(s) & g_{23}(s) & g_{24}(s) \\
g_{31}(s) & g_{32}(s) & g_{33}(s) & g_{34}(s) \\
g_{41}(s) & g_{42}(s) & g_{43}(s) & g_{44}(s)
\end{array}\right]\left[\begin{array}{c}
H_{g i}(s) \\
\theta_{g i}(s) \\
\theta_{l i}(s) \\
C_{l i}(s)
\end{array}\right]=\boldsymbol{G}(s)\left[\begin{array}{c}
H_{g i}(s) \\
\theta_{g i}(s) \\
\theta_{l i}(s) \\
C_{l 2}(s)
\end{array}\right]
$$

この $4 \times 4$ マトリクスが, この系の伝達マトリクス で, $g_{i j}(i=1, \cdots, 4, j=1, \cdots, 4)$ はその要素を示し,詳 細は文末付録に示す。一般汶対角線上に位置する伝 達要素は,

$$
\frac{e_{3} s^{3}+e_{2} s^{2}+e_{1} s+e_{0}}{a_{4} s^{4}+a_{3} s^{3}+a_{2} s^{2}+a_{1} s+a_{0}}
$$

の形となり，他の要素は次の形をとる.

$$
\frac{e_{2} s^{2}+e_{1} s+e_{0}}{a_{4} s^{4}+a_{3} s^{3}+a_{2} s^{2}+a_{1} s+a_{0}}
$$

Fig. 3 は次の数値例についてアナログ計算機を用

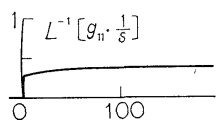

(a)

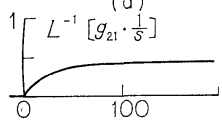

(e)
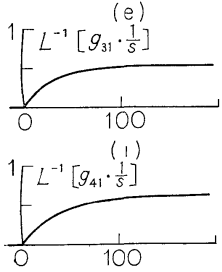

(m)

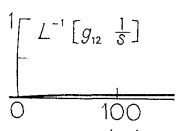

(b)

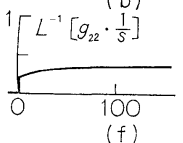

(f)

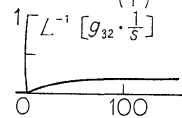

(נ)

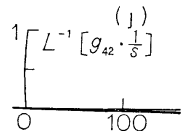

$(n)$

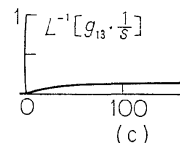

(c)

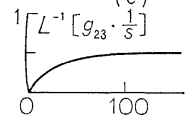

(g)

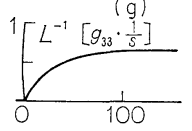

(k)

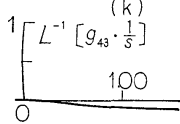

(o)

いて，ステップ応答を計算したものである. この数值 例は, 横浜国大冷暖房研究設備として設置されている 塩化りチウム脱湿装置について考えたものである. $m=0.26, n=0.0036, K_{g}=3.92, K_{l}=0.305, h_{g}=4.08$ $h_{l}=40.8, \lambda=2.60,(-\Delta H)=0.289, k=43.5, k_{2}=0.127$

この例では，相互干渉の影響が Fig. 3 (b), (c), (e), (i)，(n)，(o) 飞特湿著に現われている（相互干渉が なければここらの出力はゼロになる)。

\section{6. 熱移動之物質移動の相互干渉}
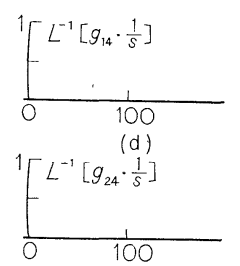

(h)

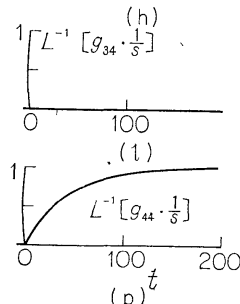

$(p)^{t}$
気液接触装置の動特性は前述 の伝達マトリクスで表わされた が, ここでは動特性の別の表現 であるブロック線図を描き，熱 移動之物質移動の相互干渉を詳 細に検討する. (22) 〜 (31) 式 を用いてブロック線図を描くと

Fig. 4 となる.

この図の上半分は物質移動を 示し，下半分は熱移動を示して 招り, 互いに3つの経路によっ て結ばれている. 熱移動の物質 移動に対する干渉は，下から上 へ向から経路のパラメータであ 


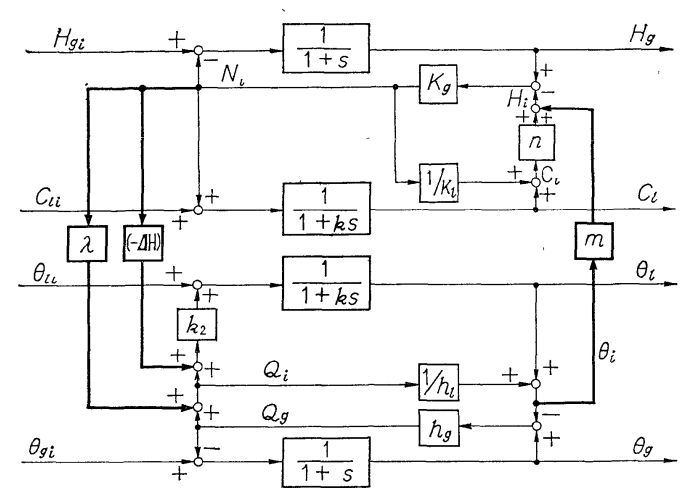

Fig. 4 Block diagram of the dehumidification process

る気液平衡関係の温度依存性 $m$ により，逆に; 物質 移動の熱移動に対する干渉は上から下へ向から経路の 凝縮熱 $\lambda$, 溶解括よび希橎熱 $(-\Delta H)$ に依存して特り, この干渉は一方向的でなくて，相互に影響を及ぼしあ っている.

したがって，一般には熱移動と物質移動を切離して は扱い得ず， 4 入力ー 4 出力系として取扱わなければな らない.

\section{$6 \cdot 1$ 熱移動のみに注目するとき}

流入流体の湿度および濃度が一定で, 温度入力だけ が変動する場合を考えよう. $H_{g i}(t)=C_{l i}(t)=0$ とし て，Fig. 4 を等価変換すると， Fig. 5 になり，単な る熱交換とは異なることがわかる.

たと光，入口の湿度，濃度変化がなくても，熱移動 にともなって, 物質移動が起こり, これが再度, 熱移 動に影響を及ぼすのである。

この熱移動にともなって起こる物質移動の存在によ る影響は，Fig. 5 のブロック線図上で太線によって 示してある.

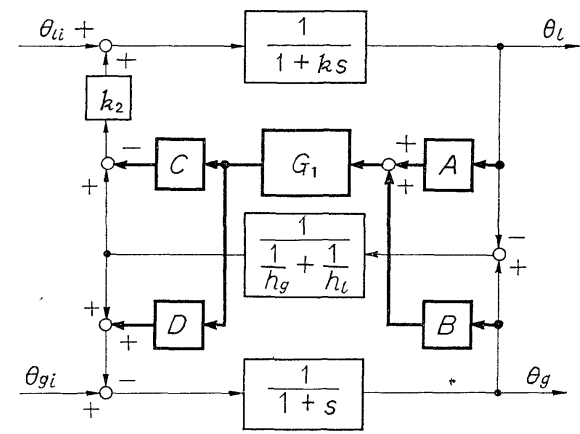

Fig. 5 Influence of mass transfer to heat transfer

Fig. 5 に郝恉る $G_{1}, A, B, C, D$ は次式で表わされる.

$$
\begin{aligned}
G_{1}= & \frac{m K_{g} K_{l}\left(h_{g}+h_{l}\right)(s+1)}{\left[K_{l}\left(h_{l}+h_{g}\right)+n K_{g}\left(h_{l}+h_{g}\right)+m \lambda K_{g} K_{l}\right] k s^{2}} \\
& \frac{(k s+1)}{+\left[\overline { K _ { l } } \left(\overline{\left.h_{l}+h_{g}\right)+n K_{g}\left(h_{l}+h_{g}\right)+m \lambda K_{g} K_{l}}\right.\right.}
\end{aligned}
$$

$$
\begin{aligned}
& \left.+K_{g} K_{l}\left(h_{g}+h_{l}\right)\right](k+) s+\left[K_{l}\left(h_{l}+h_{g}\right)\right. \\
& \left.+n K_{g}\left(h_{l}+h_{g}\right)+m \lambda K_{g} K_{l}+2 K_{g} K_{l}\left(h_{l}+h_{g}\right)\right] \\
A & =\frac{1 / h_{g}}{1 / h_{g}+1 / h_{l}}, \quad B=\frac{1 / h_{l}}{1 / h_{g}+1 / h_{l}}, \quad C=(-\Delta H \\
+ & \frac{\lambda / h_{g}}{1 / h_{g}+1 / h_{l}}, \quad D=\frac{\lambda / h_{l}}{1 / h_{g}+1 / h_{l}} .
\end{aligned}
$$

\section{$6 \cdot 2$ 物質移動のみに注目するとき}

流入流体の温度が一定で, 湿度および濃度のみが変 動する場合を考えよう. $\theta_{g i}(t)=\theta_{l i}(t)=0$ として, Fig. 4 を整理すると Fig. 6 となり, 熱移動による影 響は太線で示した $G_{2}$ のブロックによって起こる.

$$
\begin{aligned}
G_{2}=\frac{m\left[k \lambda s^{2}+\left\{\left(k+k h_{g}+k_{2} h_{l}+1\right) \lambda+k h_{l}(-\Delta H)\right\} s\right.}{k\left(h_{g}+h_{l}\right) s^{2}+\left[(k+1)\left(h_{g}+h_{l}\right)+\left(k+k_{2}\right) h_{g} h_{l}\right] s} \\
\left.+\left(1+h_{g}\right)\left\{(\lambda+(-\Delta H)) k_{2} h_{l}+\lambda\right\}\right] \\
+\left[\left(h_{g}+h_{l}\right)+\left(k_{2}+1\right) h_{g} h_{l}\right]
\end{aligned}
$$

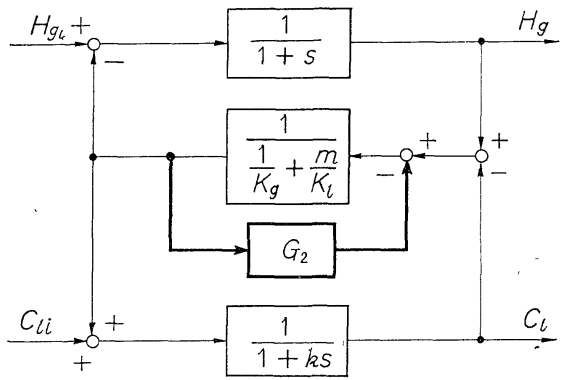

Fig. 6 Influence of heat transfer to mass transfer

Fig. 6 をさらに等価変換すると，Fig. 7 となり総 括物質移動係数の形で，熱移動による影響を論ずるこ とができる。

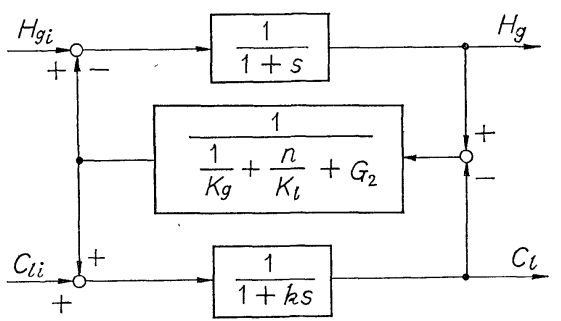

Fig. 7 Influence of heat transfer to mass transfer

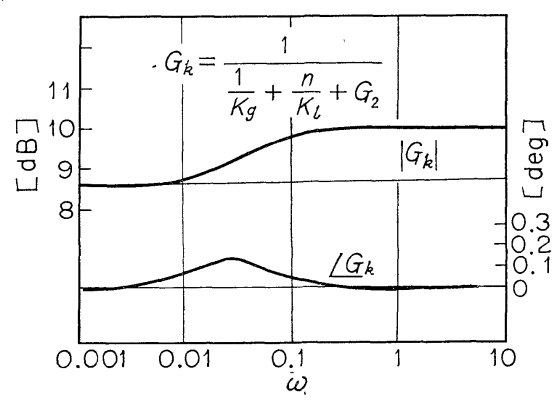

Fig. 8 Frequency characteristics of over-all mass transfer 
総括物質移動係数 $G_{k}(s)=\frac{1}{1 / K_{g}+n / K_{l}+G_{2}(s)}$

Fig. 8 は前の数値例について, 総括物質移動係数 を計算したものである. この総括物質移動係数は, 定 数とはならなくて, 伝達周波数 $\omega$ の関数となる.

$1 / K_{g}+n / K_{l} \gg G_{2}$ が成立つ周波数帯に叔いてのみ熱 移動の影響を無視することが可能になる.

\section{7. ま め}

気液接触装置の基礎式を誘導し，める平衡状態の近 傍での微小変化に対する動特性を検討した.

熱移動と物質移動の相互干渉は, 気液平衡関係の温 度依存性 $m$, 水の凝縮熱 $\lambda$, 溶解特よび希釈熱 (一 $\Delta H ）$ によって起こることが明白になった．熱移動の 物質移動に対する干渉は，Fig. 4 に示したよらに $m$ に依存し, 逆に物質移動の熱移動に対する干渉は $\lambda$ と $(-\Delta H)$ に依存している.

また，入口温度が一定で，湿度㸩よび濃度のみが変 動する場合には，総括物質移動係数の形で, 干渉を論 ずることができ，総括物質移動係数は $\lambda$ および（-A
$H ）$ の影響を受けて一定值とはならず，伝達周波数 $\omega$ の関数となることがわかった. 熱移動の影響を無視し らるかどらかの判定にはこれを用いると便利であろら。

しかし, 一般には, 熱移動と物質移動を切離しては 扱い得ず， 4 入力ー 4 出力系として取扱わなければな らない.

\section{文献}

1) T. Takamatsu, M. Hiraoka, K. Tanaka : "Simulteneous heat and mass transfer between gass and liquid phase" Int. J. Heat and Mass Transfer, Vol. 7, 621/630 (1964)

2）東畑平一郎・山田豊一・中田常雄・坂垣浩正：“多孔 板を用いた塩化りチウム水溶液による減湿についで 化学工学, 28-10, 832/835 (1964)

3) Arnold Wexler : "Measurment and Control in science and industry", Reinhold publishing Co., Vol. 1 4 (1964)

4）工業計測技術大系編集委員会編: “湿度水分測定”, （1965-日刊工業）

5）吉田文武・森 芳郎編：“詳諭化学工学 II” 朝倉書店, (1967)

(43) 式の伝達マトリクスの各要素は次のものである.

$$
\begin{aligned}
& g_{11}(s)=\left[k^{2} s^{3}+k\left\{\left(1+b_{6}\right) k+\left(2+k_{2} b_{7}+k_{3} b_{3}+b_{4}\right)\right\} s^{2}+\left\{k\left(2+k_{2} b_{7}+k_{3} b_{3}+b_{4}+k_{2} b_{4} b_{7}+k_{3} b_{2} b_{7}-b_{2} b_{8}\right)\right.\right. \\
& \left.+\left(1+k_{2} b_{7}+k_{3} b_{3}+b_{4}+k_{2} b_{4} b_{7}+k_{2} b_{3} b_{8}\right)\right\} s+\left(1+b_{6}+b_{4}+b_{4} b_{6}+k_{2} b_{7}+k_{2} b_{4} b_{7}+k_{3} b_{3}+k_{3} b_{3} b_{6}+k_{2} b_{3} b_{8}+k_{3} b_{2} b_{7}\right. \\
& \left.\left.-b_{2} b_{8}\right)\right] /|\boldsymbol{A}| \\
& g_{12}(s)=\left[k^{2} b_{2} s^{2}+k\left(2 b_{2}+k_{2} b_{2} b_{7}+k_{2} b_{3} b_{6}\right) s+\left(b_{2}+k_{2} b_{2} b_{7}+k_{2} b_{3} b_{6}\right)\right] /|\boldsymbol{A}| \\
& g_{13}(s)=\left[k b_{3} s^{2}+\left\{\left(b_{3}+b_{2} b_{7}+b_{3} b_{6}\right) k+b_{3}\right\} s+\left(b_{3}+b_{2} b_{7}+b_{3} b_{6}\right)\right] /|\boldsymbol{A}| \\
& g_{14}(s)=\left[k b_{4} s^{2}+\left\{\left(b_{4}+b_{4} b_{6}-b_{2} b_{8}\right) k+b_{4}+k_{2} b_{4} b_{7}+k_{2} b_{3} b_{8}\right\} s+\left(b_{4}+b_{4} b_{6}+k_{2} b_{4} b_{7}+k_{2} b_{3} b_{8}-b_{2} b_{8}\right)\right] /|\boldsymbol{A}| \\
& g_{21}(s)=\left[k^{2} b_{5} s^{2}+k\left(2 b_{5}+k_{3} b_{3} b_{5}+b_{4} b_{5}+k_{3} b_{1} b_{7}-b_{1} b_{8}\right) s+\left(b_{5}+k_{3} b_{3} b_{5}+b_{4} b_{5}+k_{3} b_{1} b_{7}-b_{1} b_{8}\right)\right] /|\boldsymbol{A}| \\
& g_{22}(s)=\left[k^{2} s^{3}+k\left\{\left(1+b_{1}\right) k+\left(2+b_{4}+k_{2} b_{7}+k_{3} b_{3}\right)\right\} s^{2}+\left\{k\left(2+2 b_{1}+b_{4}+k_{2} b_{7}+k_{3} b_{3}+k_{2} b_{1} b_{7}+k_{2} b_{3} b_{5}\right)\right.\right. \\
& \left.\left.+\left(1+k_{2} b_{7}+k_{3} b_{3}+b_{4}+k_{2} b_{4} b_{7}+k_{2} b_{3} b_{8}\right)\right\} s+\left(1+k_{2} b_{7}+k_{3} b_{3}+b_{1}+k_{2} b_{1} b_{7}+b_{4}+k_{2} b_{4} b_{7}+k_{2} b_{3} b_{8}+k_{2} b_{3} b_{5}\right)\right] /|\boldsymbol{A}| \\
& g_{23}(s)=\left[k b_{7} s^{2}+\left\{\left(b_{7}+b_{1} b_{7}+b_{3} b_{5}\right) k+\left(b_{7}+b_{4} b_{7}+b_{3} b_{8}\right)\right\} s+\left(b_{7}+b_{1} b_{7}+b_{3} b_{5}+b_{4} b_{7}+b_{3} b_{8}\right)\right] /|\boldsymbol{A}| \\
& g_{24}(s)=\left[-k b_{8} s^{2}-\left\{k\left(b_{8}+b_{1} b_{8}-b_{4} b_{5}\right)+b_{8}+k_{3} b_{3} b_{8}+k_{3} b_{4} b_{7}\right\} s-\left(k_{3} b_{4} b_{7}-b_{4} b_{5}+b_{8}+b_{1} b_{8}+k_{3} b_{3} b_{8}\right)\right] /|\boldsymbol{A}| \\
& g_{31}(s)=\left[k\left(k_{3} b_{1}-k_{2} b_{5}\right) s^{2}+\left\{k\left(k_{3} b_{1}-k_{3} b_{1} b_{6}-k_{3} b_{2} b_{5}-k_{2} b_{5}\right)+\left(k_{3} b_{1}-k_{2} b_{5}+k_{2} b_{1} b_{8}-k_{2} b_{4} b_{5}\right)\right\} s+\left(k_{3} b_{1}-k_{2} b_{5}+k_{3} b_{1} b_{6}\right.\right. \\
& \left.\left.-k_{3} b_{2} b_{5}+k_{2} b_{1} b_{8}-k_{2} b_{4} b_{5}\right)\right] /|\boldsymbol{A}| \\
& g_{32}(s)=\left[k\left(k_{3} b_{2}-k_{2} b_{6}\right) s^{2}+\left\{\left(k_{2} b_{6}-k_{3} b_{2}+k_{2} b_{1} b_{6}-k_{2} b_{2} b_{5}\right) k+\left(k_{2} b_{6}+k_{2} b_{4} b_{6}-k_{3} b_{2}-k_{2} b_{2} b_{8}\right)\right\} s+\left(k_{3} b_{2}-k_{2} b_{6}+k_{2} b_{2} b_{5}\right.\right. \\
& \left.\left.-k_{2} b_{1} b_{6}-k_{2} b_{4} b_{6}\right)\right] /|\boldsymbol{A}|
\end{aligned}
$$




$$
\begin{aligned}
& g_{33}(s)=\left[k s^{3}+\left\{k\left(2+b_{1}+b_{6}\right)+1+b_{4}\right\} s^{2}+\left\{k\left(1+b_{1}+b_{6}+b_{1} b_{6}-b_{2} b_{5}\right)+\left(2+b_{1}+b_{6}+2 b_{4}+b_{4} b_{6}-b_{2} b_{8}\right)\right\} s+\left(1+b_{1}\right.\right. \\
& \left.\left.+b_{6}+b_{1} b_{6}+b_{4}+b_{4} b_{6}-b_{2} b_{8}-b_{2} b_{5}\right)\right] /|\boldsymbol{A}| \\
& g_{34}(s)=\left[-\left(-k_{2} b_{8}+k_{3} b_{4}\right) s^{2}-\left(-2 k_{2} b_{8}-k_{2} b_{1} b_{8}+2 k_{3} b_{4}+k_{3} b_{4} b_{6}-k_{3} b_{2} b_{8}+k_{2} b_{4} b_{5}\right) s-\left(-k_{2} b_{8}-k_{2} b_{1} b_{8}+k_{3} b_{4}+k_{3} b_{4} b_{6}\right.\right. \\
& \left.\left.-k_{3} b_{2} b_{8}+k_{2} b_{4} b_{5}\right)\right] /|\boldsymbol{A}| \\
& g_{41}(s)=\left[k b_{1} s^{2}+\left\{\left(b_{1}+b_{1} b_{6}-b_{2} b_{5}\right) k+\left(b_{1}+k_{2} b_{1} b_{7}+k_{2} b_{3} b_{5}\right)\right\} s+\left(b_{1}+b_{1} b_{6}-b_{2} b_{5}+k_{2} b_{1} b_{7}+k_{2} b_{3} b_{5}\right)\right] /|\boldsymbol{A}| \\
& g_{42}(s)=\left[-k b_{2} s^{2}-\left(b_{2}+k_{2} b_{2} b_{7}+k_{2} b_{3} b_{6}\left(s-\left(b_{2}+k_{2} b_{2} b_{7}+k_{2} b_{3} b_{6}\right)\right] /|\boldsymbol{A}|\right.\right. \\
& g_{43}(s)=\left[-b_{3} s^{2}-\left(2 b_{3}+b_{3} b_{6}+b_{2} b_{7}\right) s-\left(b_{3}+b_{3} b_{6}+b_{2} b_{7}\right)\right] /|\boldsymbol{A}| \\
& g_{44}(s)=\left[k s^{3}+\left\{k\left(2+b_{1}+b_{6}\right)+\left(1+k_{2} b_{7}+k_{3} b_{3}\right)\right\} s^{2}+\left\{k\left(1+b_{1}+b_{6}+b_{1} b_{6}\right)+\left(2+b_{1}+b_{6}+2 k_{2} b_{7}+k_{2} b_{1} b_{7}+2 k_{3} b_{3}\right.\right.\right. \\
& \left.\left.\left.+k_{3} b_{3} b_{6}+k_{3} b_{2} b_{7}+k_{2} b_{3} b_{5}\right)\right\} s+\left(1+b_{1}+b_{6}+b_{1} b_{6}+k_{2} b_{7}+k_{2} b_{1} b_{7}+k_{3} b_{3}+k_{3} b_{3} b_{6}+k_{3} b_{2} b_{7}-b_{2} b_{5}+k_{2} b_{3} b_{5}\right)\right] /|\boldsymbol{A}| \\
& |\boldsymbol{A}|=k^{2} s^{4}+\left[k^{2}\left(2+b_{1}+b_{6}\right)+k\left(2+b_{4}+k_{3} b_{3}+k_{2} b_{7}\right)\right] s^{3}+\left[k^{2}\left(1+b_{1}+b_{6}+b_{1} b_{6}-b_{2} b_{5}\right)+k\left\{\left(2 b_{3}+b_{3} b_{6}+b_{2} b_{7}\right) k_{3}+\left(2 b_{7}\right.\right.\right. \\
& \left.\left.\left.+b_{1} b_{7}+b_{3} b_{5}\right) k_{2}+\left(2 b_{4}+b_{4} b_{6}+b_{2} b_{8}+4+2 b_{1}+2 b_{6}\right)\right\}+b_{3} k_{3}+\left(b_{7}+b_{4} b_{7}-b_{3} b_{8}\right) k_{2}+1+b_{4}\right] s^{2}+\left[k \left\{\left(b_{3}+b_{3} b_{6}\right.\right.\right. \\
& \left.\left.+b_{2} b_{7}\right) k_{3}+\left(b_{7}+b_{1} b_{7}+b_{3} b_{5}\right) k_{2}+\left(b_{4}+b_{4} b_{6}+b_{2} b_{8}+2+2 b_{1}+2 b_{6}+2 b_{1} b_{6}-2 b_{2} b_{5}\right)\right\}+\left\{\left(2 b_{3}+b_{3} b_{6}+b_{2} b_{7}\right) k_{3}\right. \\
& \left.\left.+\left(2 b_{7}+b_{1} b_{7}+b_{3} b_{5}+2 b_{4} b_{7}-2 b_{3} b_{8}\right) k_{2}+\left(2 b_{4}+b_{4} b_{6}+b_{2} b_{8}+2+b_{1}+b_{6}\right)\right\}\right] s+\left[\left(b_{3}+b_{3} b_{6}+b_{2} b_{7}\right) k_{3}+\left(b_{7}+b_{1} b_{7}\right.\right. \\
& \left.+b_{3} b_{5}+b_{4} b_{7}-b_{3} b_{8}\right) k_{2}+\left(b_{4}+b_{4} b_{6}+b_{2} b_{8}+1+b_{1}+b_{6}+b_{1} b_{6}-b_{2} b_{5}\right)
\end{aligned}
$$

